\title{
Study and Analysis of Nonlinear Constrained Components (A Study of Plug-in Hybrid Electric Vehicle)
}

\author{
Sadia Andaleeb \\ M.Tech Scholar, Department of Mechanical Engineering, \\ E-MAX, Group of Institutions, Gola, Ambala, Tamil Nadu, India
}

\begin{abstract}
Today transportation is one of the rapidly evolving technologies in the world. With the stringent mandatory emission regulations and high fuel prices, researchers and manufacturers are ever increasingly pushed to the frontiers of research in pursuit of alternative propulsion systems. Electrically propelled vehicles are one of the most promising solutions among all the other alternatives, as far as; reliability, availability, feasibility and safety issues are concerned. However, the shortcomings of a fully electric vehicle in fulfilling all performance requirements make the electrification of the conventional engine powered vehicles in the form of a plug-in hybrid electric vehicle (PHEV) the most feasible propulsion systems.
\end{abstract}

\section{KEYWORDS: PHEV, PSO, HEV, AER, CDR.}

\section{INTRODUCTION}

Plug-in Hybrid Electric Vehicles (PHEV) link two major infrastructures, the transportation and the electric power grid. They offer a promise of significant reduction of fuel consumption, oil imports, and $\mathrm{CO} 2$ emissions by bringing other sources of energy into transportation. PHEVs are similar to conventional Hybrid Electric Vehicles (HEV) in that they utilize an electric motor and a gasoline engine as two drives to power a vehicle, but they have much larger batteries that can be charged from an electrical outlet. The electrical energy stored in the battery is used as the primary source of power on-board until the battery charge is depleted to a threshold level. This mode of powertrain operation is called the charge depleting (CD) mode or electric vehicle (EV) mode. After charge depletion to the threshold level the internal combustion engine is used to sustain the charge at this level. This is referred to as the charge sustaining mode (CS) mode. The all-electric range (AER) or the charge depleting range (CDR) of a PHEV is the distance over which the powertrain operates in EV or CD mode respectively and this has been recognized a very relevant attribute for PHEVs [1] [2] [3]. The engine fuel consumption during this mode is very low or zero. This has led to classification of PHEVs as PHEV 10 (A PHEV with 10 miles CDR/AER), PHEV 20 and so on. If pure AER is desired, a Series Hybrid Electric Vehicle configuration is particularly interesting. However, many design decisions have to be made to maximize the potential of a given configuration for a selected vehicle application. A hybrid electrical vehicle could be a variety of hybrid vehicle that utilizes the mixture of a standard combustion engine system and electrical system. The existence of electrical system is meant to boost the fuel economy, scale back waste material emissions and/or improve the performance. The idea of hybrid electrical vehicle (HEV) belongs to academic. Ferdinand Porsche in 1899 succeeding thirty years makers created numerous ideas. This technology wasn't a middle of interest once the first development amount for an extended time. However, in 1990s, researchers and makers started intensely leaning on raising the HEV technology. Its potential of being extremely fuel-efficient and considerably low levels of emissions created this technology one in all the brightest analysis subjects of the age.

\section{Problem Definition}

The problem arises from the search for a better fuel economy whilst meeting the performance requirements. The search for a better configuration of drivetrain components in terms of fuel economy and better performance is an openended research subject. Continuous improvement in this field is a significant technical achievement that should be taken care of. Since the vehicle itself is dynamically, highly, nonlinear and most of the drivetrain components in a PHEV, directly or indirectly, has an effect on each other, optimization process of the major powertrain components have to be done via proper methodology to represent effects of each component modification on the others. In order to explain this effect briefly, for example, if the engine on the vehicle is decided to be more powerful, changing the existing engine with a $20 \%$ more powerful engine will increase the total mass of the vehicle because the bigger engine's block mass will be higher than the replaced one. Therefore, each and every component's effect has to be considered. The objective of using an optimization tool is explained to express the effects of all the components on the others and on themselves mathematically in the optimization methodology structure.

\section{Methodology Optimization Methodology}

This section is explained in two different subsections. The first one is advantages of PSO tool and why it is chosen for this research and the second subsection describes briefly the PSO optimization tool.

\section{Advantages of PSO}

Using gradient-based algorithms the optimization problem could be solved [3]. However, since these algorithms depend on the gradients to find the optimum solution, they do not always give the global maximum or minimum as the solution. Therefore, derivative free algorithms such as Genetic Algorithm (GA), DIRECT, Dynamic Programming, Simulated Annealing, Particle Swarm Optimization, etc. can be used. Since they aren't gradient-based, they provide global solution to the optimization problem. Most evolutionary techniques mentioned above shares some common procedure, such as: random generation of initial 
population, reckoning of a fitness value for each subject, reproduction of the population. However, PSO does not have genetic operators like mutation and crossover [14]. Particles update themselves with the internal velocity. Also each particle has a memory, which is significant for the algorithm. The information sharing mechanism of PSO tool is significantly different than the others. Instead of having massive amount of variables to tell the system about the previous iteration, PSO has just one variable to rule that functionality to the algorithm. It is simply a one-way information sharing mechanism. Another major advantage of PSO tool is that the method only searches for the best solution and at the end all the particles converge to the best solution quickly in most cases [23]. Strengths and advantages of the PSO tool mentioned in above paragraphs over the other gradient based algorithms, made this tool the most convenient optimization algorithm to work with a highly nonlinear and component dependent system like PHEV.

\section{Particle Swarm Optimization}

Particle Swarm optimization was developed by Kennedy and Eberhart in 1995 [14]. The algorithm is based on the social behavioral model of the society, similar to the social behaviors of bird flocking or fish schooling; in other words, it is based on the stochastic optimization technique. The difference of this method from the other evolutionary computation techniques, like Genetic Algorithm (GA), is that it does not use evolution operators, such as mutation, crossover and etc. The system is initialized with a population of particles with their own position and velocity values in ndimensional space. Each particle in the solution space is a possible optimum solution.

\section{Results}

\section{PSAT/Simulink}

The mathematical model of the vehicle that was explained in the previous chapters of this thesis is constructed as block diagrams in PSAT software [15]. PSAT is a powerful simulation tool based on Matlab/Simulink. The default Toyota Prius vehicle model in PSAT is used in this research to compute major parameter values that are used in the optimization tool. Since Toyota Prius is a HEV, the model had to be modified to represent a PHEV model.

\section{MATLAB}

Matlab is very powerful simulation tool and in this work will be used to join the PSAT/SIMULINK block diagram structure with the PSO optimization tool. The PSO script is embedded in the Matlab script which runs the simulation software PSAT/SIMULINK to compute necessary parameters. Since the system is highly nonlinear and the vehicle model is complicated model, to achieve more desired results complete vehicle model simulation is used to determine the fuel consumption and the emission levels according to various random component sizes in their own boundaries. the following figure shows "Evaluate Fitness function for each particle" portion of the constrained PSO algorithm flow chart.

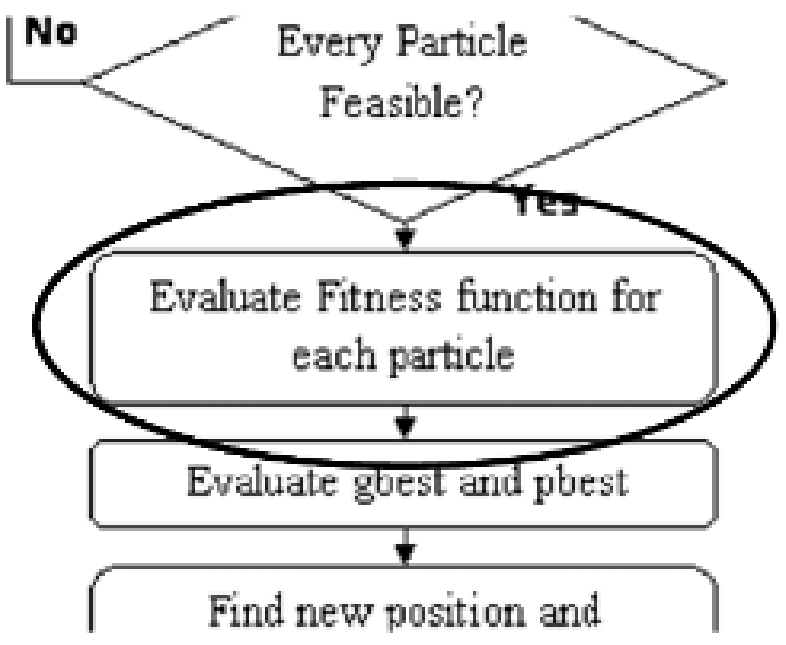

Evaluate Objective Function' portion of PSO algorithm flow chart

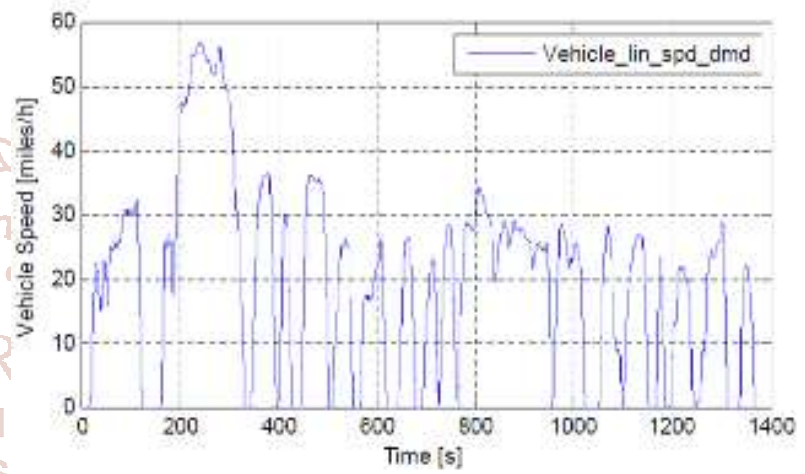

UDDS drive cycle velocity profile over time

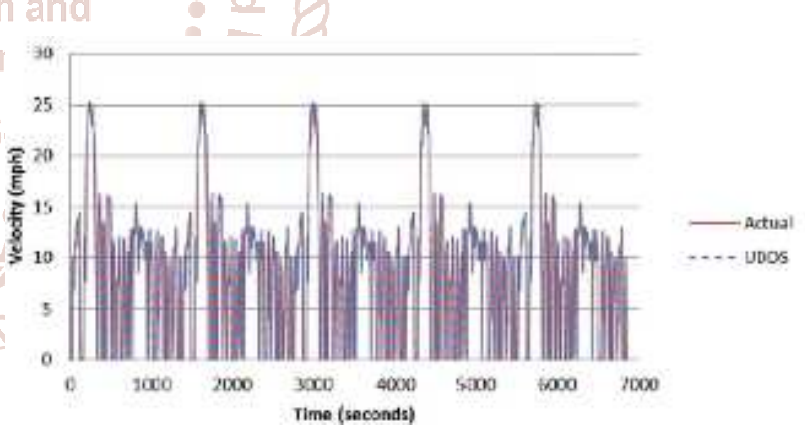

UDDS velocity profile vs. actual velocity profile

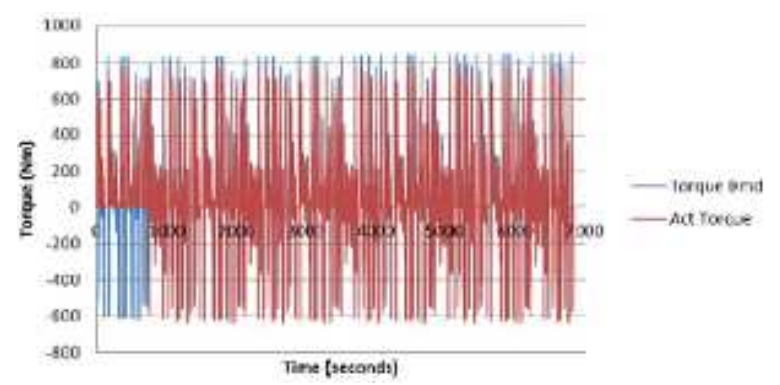

Driver cycle torque demand vs. actual final drive torque 
International Journal of Trend in Scientific Research and Development (IJTSRD) @ www.ijtsrd.com eISSN: 2456-6470
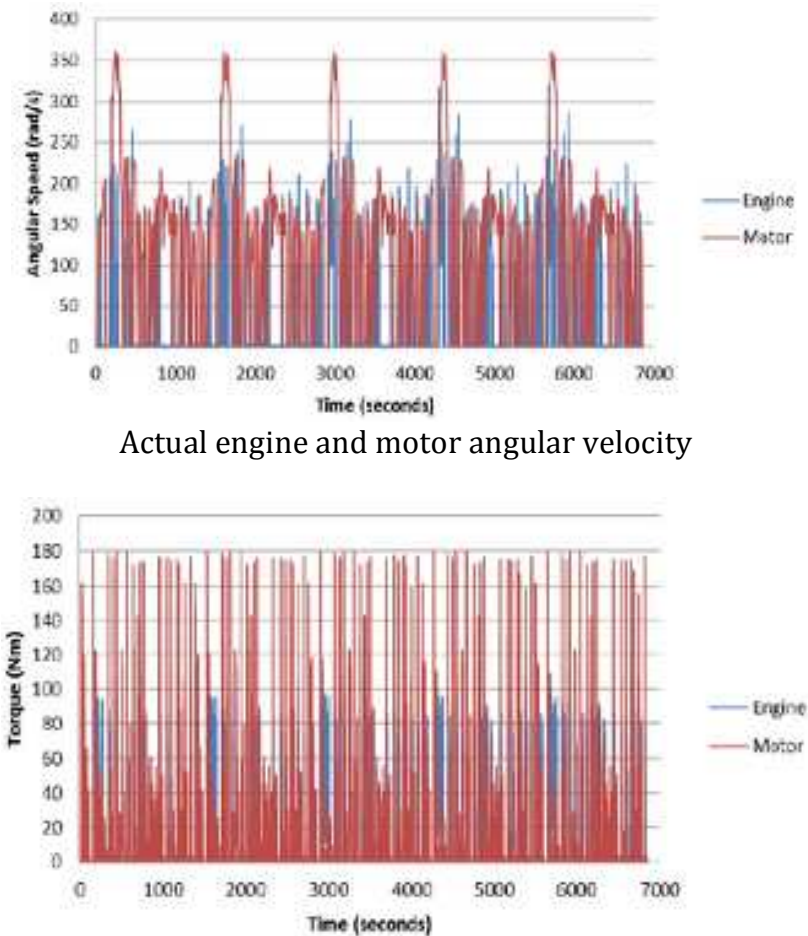

Actual engine and motor angular torque

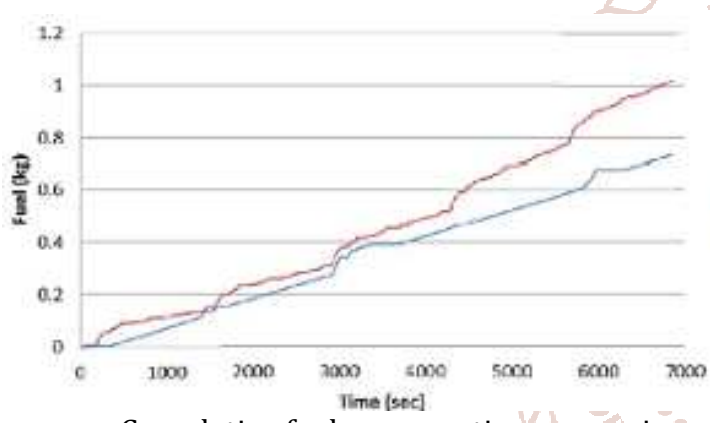

Cumulative fuel consumption comparison

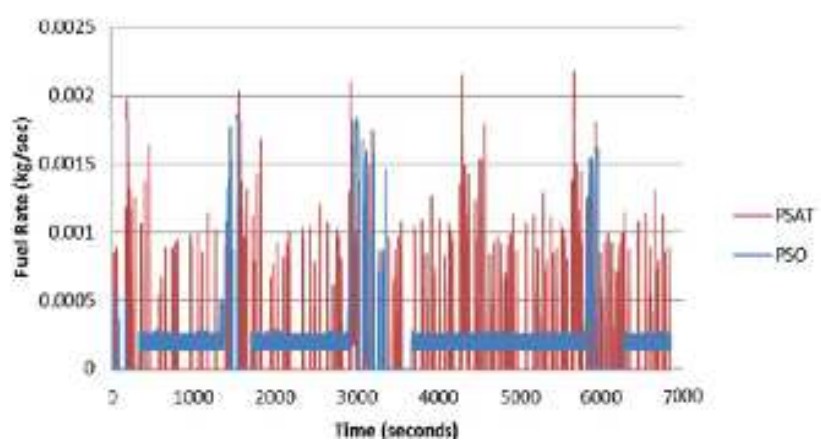

Instantaneous fuel consumption comparison

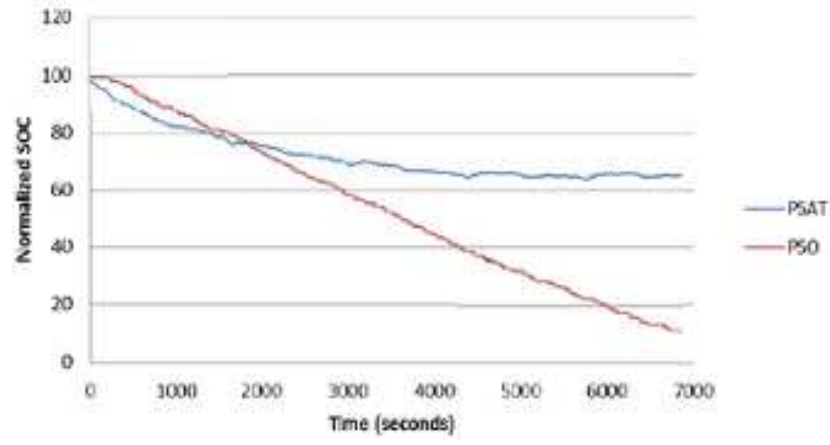

State of Charge (SOC) Comparison plot

\section{Conclusion:}

The gradient free algorithm, e.g., the particle swarm optimization was used to determine the optimal configuration of the component sizes to achieve a better fuel economy and emission levels. Therefore, a simplified model of a power split plug-in hybrid electric vehicle powertrain was developed for a plug-in hybrid electric vehicle in PSAT.

\section{References:}

[1] J.P. Norbye and J. Dunne, "Hybrid Car Ready in 1969" Popular Science, p. 86-7, Jul. 1969.

[2] D. Assanis, G. Delagrammatikas, R. Fellini, Z. Filipi, J. Liedtke, N. Sales, and M. Sasene, "An optimization approach to hybrid electric propulsion system design," Mech Struct Machines, 1999, 27(4), p. 393-421

[3] R. Fellini, N. Michelena, P. Papalambros, and M. Sasena, "Optimal design of automotive hybrid powertrain systems," Proceedings of International Symposium ON Environmentally Conscious Design and Inverse Manufacturing EcoDesign'99, p. 400-405.

[4] V. Galdi, L. Ippolito, A. Piccolo, and A. Vaccaro, "A Genetic-Based Methodology for Hybrid Electric Vehicles Sizing," Soft Computing 6, Springer-Verlag 2001.

[5] M. Montazeri-Gh, and A. Poursamad, "Optimization of component sizes in hybrid electric vehicle via genetic algorithms," IMECE, ASME International Mechanical Engineering Congress and Exposion, Orlando, USA, 2005.

[6] Z. Zhengli, Z. Jianwu, and Y. Chengliang, "Optimization Approach for Hybrid Electric Vehicle Powertrain Design," Chinese Journal of Mechanical Engineering, Vol. 18, No. 1, p. 30-36, 2005.

[7] X. Liu, Y. Wu, and J. Duan, "Optimal Sizing of a Series Hybrid Electric Vehicle Using a Hybrid Genetic Algorithm," Proceedings of the IEEE, International Conference on Automation and Logistics, Jinan, China, August 18 - 21, 2007.

[8] A. Hasanzadeh, B. Asaei and A. Emadi. "Optimum design of series hybrid electric buses by genetic algorithm," IEEE ISIE 2005, Dubrovnik, Croatia, p.1465-1470, June 2005.

[9] T. Markel, K. Wipke, "Optimization techniques for hybrid electric vehicle analysis using ADVISOR, "Proceedings of the ASME International Mechanical Engineering Congress and Exposition. New York, November 11-16, 2001.

[10] X. Wu, B. Cao, J. Wen, and Z. Wang, "Application of Particle Swarm Optimization for Component Sizes in Parallel Hybrid Electric Vehicles," IEEE Congress on Evolutionary Computation, p. 2874-2878, 2008.

[11] W. Gao and S. K. Porandla, "Design Optimization of a Parallel Hybrid Electric Powertrain," IEEE Vehicle Power and Propulsion Conference, VPPC, p. 530-535, 2005.

[12] H. Banvait, S. Anwar and Y. Chen, "Plug-in Hybrid Electric Vehicle Energy Management System using Particle Swarm Optimization," EVS24, Stavanger, Norway, May 13 - 16, 2009. 
International Journal of Trend in Scientific Research and Development (IJTSRD) @ www.ijtsrd.com eISSN: 2456-6470

[13] H. Banvait, S. Anwar and Y. Chen, "A Rule-Based Energy Management Strategy for Plug-in Hybrid Electric Vehicle," American Control Conference, St Louis, Missouri, June 10-12, 2009.

[14] J. Kennedy and R. Eberhart, "Particle Swarm Optimization," Neural Networks, Proceedings, IEEE International Conference, Vol. 4, Pages1942-1948, 1995.

[15] Powertrain Systems Analysis Toolkit Documentation, Argonne National Laboratory, 2008.

[16] Q. Cao, S. Pagerit, R. B. Carlson, A. Rousseau, PHEV Hymotion Prius Model Validation and Control Improvements, EVS23, Anaheim, California, Dec 2-5, 2007.

[17] K. E. Parsopuulos and M. Vrahatis, "Particle Swarm Optimization Method for Constrained Optimization Problems," Intelligent Technologies- Theory and application, IOS Press, p. 214-220, 2002.

[18] X. Wu, B. Cao, J. Wen, and Y. Bian, "Particle Swarm Optimization for Plug-in Hybrid Electric Vehicle Control Strategy Parameter," IEEE Vehicle Power and Propulsion Conference (VPPC), Harbin, China, Sept 3-5, 2008.

[19] Brasington, Leigh. "A Brief History of the Hybrid Vehicle." November, 2005. www.geocities.com/Tokyo/6774/hybrid.htm. March, 2006.

[20] Durbin, Dee-Ann. "New Hybrids rolled out, but will sales keep up the pace?" Associated Press. January 6 2006.

[21] Argonne National Laboratory. "Powertrain Systems Analysis Toolkit v. 6.0."

[22] Comparing Benefits and Impacts of Hybrid Electric Vehicle Options." EPRI, Palo Alto, CA: 2001. 1000349.

[23] Markel, Tony and Keith Wipke. "Modeling GridConnected Hybrid Electric Vehicles Using ADVISOR." National Renewable Energy Laboratory. IEEE, 2001.

[24] Advanced Batteries for Electric-Drive Vehicles: A Technology and Cost-Effectiveness Assessment for Battery Electric Vehicles, Power Assist Hybrid Electric Vehicles, and Plug-In Hybrid Electric Vehicles." EPRI, Palo Alto, CA: 2004. 1009299.

[25] Balch, Robert, Andy Burke, and Andy Frank. "The Affect of Battery Pack Technology and Size Choices on Hybrid Electric Vehicle Performance and Fuel Economy."IEEE, 2001.

[26] T/J Technologies. "Synthesis of High Capacity Sn/MOx Nano Composite Anode Materials for Lithium
Rechargeable

Batteries."

www.tjtechnologies/research/batteries. March, 2006.

[27] ThermoAnalitics, Inc. "Battery Types and Characteristics."

www.thermoanalytics.com/support/publications/batt erytypesdoc.html. April 2006.

[28] Altair Nanotechnologies. "Press Release: High Performance Li Ion Battery.” January 23, 2006.

[29] The Car and Fuel of the Future: A Technology and Policy Overview." Center for Energy and Climate Solutions. National Commission on Energy Policy. June 2004.

[30] Hu, Patricia and Jennifer R. Young. "Summary of Travel Trends. 1995 Nationwide Personal Transportation Survey." December 29, 1999. US Department of Transportation and Federal Highway Administration. Oak Ridge National Laboratory.

[31] Davis, Stacy C. and Susan W. Diegal. "Transportation Energy Data Book Edition 24." US Department of Energy. Center for Transportation Analysis, Oak Ridge National Laboratory. December 2004.

[32] Hellman, Karl and Robert M. Heavenrich. "Light Duty Automotive Technology and Fuel Economy Trends: 1975 Through 2004." EPA. April 2004. EPA420-R-04001.

[33] Pulkrabek, William W. "Engineering Fundamentals of the Internal Combustion Engine: Second Edition." Pearson Prentice Hall: Upper Saddle River, New Jersey. 2004.

[34] Corrigan, Dennis. "Data for Ovonic M108 NiMH." Ovonics. Included in PSATv6.0. Initialization file: ess_nimh_60_300_ovonic.m.

[35] 7 University of Illinois. "Johnson Controls 12-95 lead-acid data." Included in PSATv6.0. Initialization file: ess_pb_28_150.m.

[36] Rousseau, A. "Saft Li-Ion". Included in PSATv6.0. Initialization file: ess_li_6_75_saft.m.

[37] Besnier, F. "MY01 US Prius engine." Included in PSATv6.0. Initialization file: eng_si_1500_52_USPrius.m.

[38] Rousseau, A. and Paryani, Anil. "Data for permanent magnet electric motor from Honda." Included in PSATv6.0. Honda R\&D Americas. Initialization file: mc_pm_49_49_Honda.m.

[39] Electric Information Administration. "Electric Power Annual Overview." http://www.eia.doe.gov/cneaf/electricity/epa/epa_su m.html. April 2006. 